\title{
Detection of colorectal cancer biomarkers in the presence of interfering gases
}

\author{
G. Zonta ${ }^{\mathrm{a}, \mathrm{c}, *}$, G. Anania ${ }^{\mathrm{d}}$, B. Fabbri ${ }^{\mathrm{a}, \mathrm{c}}$, A. Gaiardo $^{\mathrm{a}, \mathrm{e}}$, S. Gherardi ${ }^{\mathrm{a}}$, \\ A. Giberti ${ }^{a, b}$, V. Guidi ${ }^{a, b, c}$, N. Landini ${ }^{a}$, C. Malagù ${ }^{a, c}$ \\ a Department of Physics and Earth Science, University of Ferrara, Via Saragat 1/c, 44122 Ferrara, Italy \\ ${ }^{\mathrm{b}}$ MIST E-R s.c.r.l., Via P. Gobetti 101, 40129 Bologna, Italy \\ c CNR-INO - Istituto Nazionale di Ottica, Largo Enrico Fermi 6, 50124 Firenze, Italy \\ d Department of Morphology, Surgery and Experimental Medicine, University of Ferrara, Via Luigi Borsari, 46, 44121 Ferrara, Italy \\ e MNF - Micro Nano Facility, Bruno Kessler Foundation, Via Sommarive 18, 38123 Trento, Italy
}

\section{A R T I C L E I N F O}

\section{Article history:}

Available online 18 May 2015

\section{Keywords:}

VOC

Colorectal cancer

Sensor

Benzene

1-Iodo-nonane

Decanal

\begin{abstract}
A B S T R A C T
Medical studies have shown that tumor growth is accompanied by protein changes that may lead to the peroxidation of the cell membrane, with consequent emission of volatile organic compounds (VOCs). VOCs can be detected through breath or intestinal gases and are biomarkers for colorectal cancer (CRC). The analysis of VOCs represents a non-invasive and potentially inexpensive pre-screening technique. An array of chemoresistive gas sensors, based on screen-printed Metal OXide (MOX) semiconducting films, has been selected to identify gaseous compounds of oncological interest, i.e. benzene, 1-iodo-nonane and decanal, from the main interferers that can be found in the intestine. MOX sensors are able to detect concentrations down to about 10 th ppb, as experimentally proven in previous works, so they can identify very slight differences in concentration among gas mixtures. In this work it has been proven that the array used is able to identify tumor markers singularly and in combination with other gases both in wet and dry conditions. Moreover, the sensors chosen can discriminate target VOCs from interferers even at low concentrations.
\end{abstract}

(c) 2015 Elsevier B.V. All rights reserved.

\section{Introduction}

Nano-materials can offer promising non-invasive methods to detect and prevent cancer [1]. It is known that VOCs emissions, produced by the peroxidation of the cell membrane or by cellular metabolism, are linked to tumor presence and growth and they can be detected directly from the headspace of cancer cells or through exhaled breath $[2,3]$. Indeed, changes in the blood chemistry lead to measurable modifications in the breath composition due to exchanges inside the lungs, e.g. in the range of $20-100 \mathrm{ppb}$ for several VOCs [4], as well as in feces from normal digestion [5]. Aim of this work is to study the detection of VOCs indicators of CRC, identifying the most selective sensors for these compounds, in order to analyze intestinal gases in which these biomarkers should convey.

\footnotetext{
is Selected papers presented at EUROSENSORS 2014, the XXVIII edition of the conference series, Brescia, Italy, September 7-10, 2014.

* Corresponding author at: Department of Physics and Earth Science, University of Ferrara, Via Saragat 1/c, 44122 Ferrara, Italy. Tel.: +39 0532974286.

E-mail address: giulia.zonta@unife.it (G. Zonta).
}

The most relevant VOCs which may indicate CRC presence are benzene compounds, 1-iodo-nonane $\left(\mathrm{C}_{9} \mathrm{H}_{19} \mathrm{I}\right)$ and decanal $\left(\mathrm{C}_{10} \mathrm{H}_{20} \mathrm{O}\right)$ [4-6]. The main gases that can interfere in this context are $\mathrm{H}_{2}, \mathrm{CH}_{4}$, $\mathrm{H}_{2} \mathrm{~S}, \mathrm{SO}_{2}, \mathrm{~N}_{2}, \mathrm{NO}_{2}$ and $\mathrm{NO}$, these being the main components of the intestinal gas mixture.

\section{Material and methods}

\subsection{Sensors properties}

We tested several MOX for this dedicated experiment, and the selected sensing materials, the most promising ones, as confirmed by the reported data, are listed in Table 1 . Sensors are prepared via screen-printing technique, after the deposition of the MOX paste on alumina substrate. They are provided with a heater made of platinum on the backside, while the contacts are made of gold. The screen-printing procedure is reported in Printed films: Materials science and applications in sensors, electronics and photonics [11].

A typical screen consists of a network of finely twisted steel wires (of $100 \mu \mathrm{m}$ ), stretched over a frame of aluminum. Sensors have been electrically characterized in a laboratory setup using gas 
Table 1

Composition of the metal-oxide sensors chosen for the array.

\begin{tabular}{|c|c|c|}
\hline Name & Film composition & Firing temperature $\left({ }^{\circ} \mathrm{C}\right)$ \\
\hline ST20 650 & $\mathrm{SnO}_{2}, \mathrm{TiO}_{2}(20 \%)$ & 650 \\
\hline ST25 650 & $\mathrm{SnO}_{2}, \mathrm{TiO}_{2}(25 \%)$ & 650 \\
\hline ST25 + Au1\% & $\mathrm{SnO}_{2}, \mathrm{TiO}_{2}(25 \%), \mathrm{Au}(1 \%)$ & 650 \\
\hline ST30 650 & $\mathrm{SnO}_{2}, \mathrm{TiO}_{2}(30 \%)$ & 650 \\
\hline $\mathrm{ZnO} 650$ & $\mathrm{ZnO}$ & 650 \\
\hline ZnO 850 & $\mathrm{ZnO}$ & 850 \\
\hline TiTaV & $\mathrm{TiO}_{2}, \mathrm{Ta}_{2} \mathrm{O}_{5}$, vanadium oxide & 650 \\
\hline STN & $\mathrm{SnO}_{2}, \mathrm{TiO}_{2}, \mathrm{Nb}_{2} \mathrm{TiO}_{7}$ & 650 \\
\hline
\end{tabular}

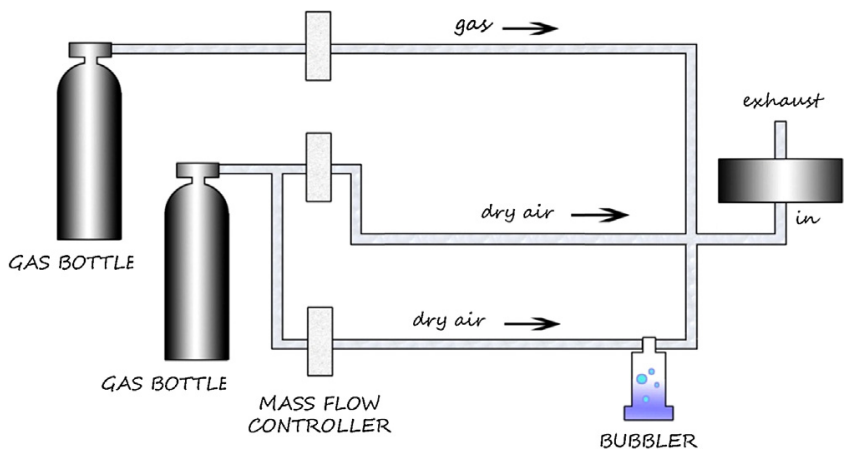

Fig. 1. Scheme of the experimental setup for gases from bottles. The bottles are connected to mass flow controllers. The first line conveys the target gas (e.g. $\mathrm{C}_{6} \mathrm{H}_{6}$ or interferers), the second line conveys dry air, the third one is employed once the measure is taken in wet conditions. Air and gases arrive at the sensors chamber.

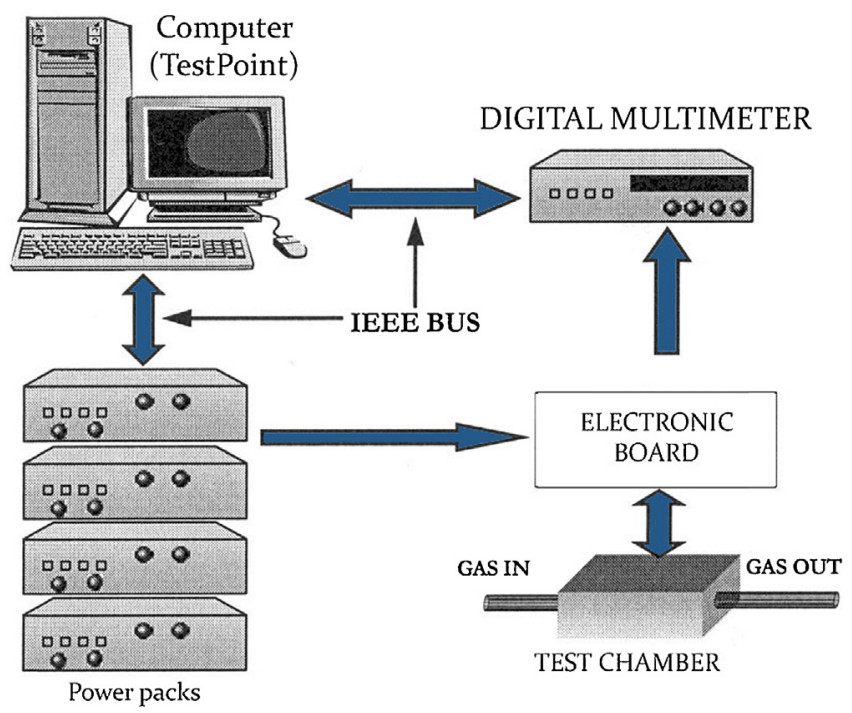

Fig. 2. Laboratory setup.

bottles as origin for gas targets and interferences. The system is sketched in Fig. 1, while the setup for the acquisition of the signal is shown in Fig. 2.

We selected $\mathrm{ZnO}$ (with two different thermal treatments, 650 and $850^{\circ} \mathrm{C}$ ), four solid solutions of $\mathrm{SnO}_{2}$ and $\mathrm{TiO}_{2}$, a solution of $\mathrm{TiO}_{2}, \mathrm{Ta}_{2} \mathrm{O}_{5}$ and vanadium oxide and a solution of $\mathrm{SnO}_{2}, \mathrm{TiO}_{2}$ and $\mathrm{Nb}_{2} \mathrm{TiO}_{7}$ (all these material were treated thermally at $650^{\circ} \mathrm{C}$ ). The annealing temperatures synthesis and structural, morphological and thermal characterizations of these nanostructured materials are reported in literature [7-9]. The increase of the firing temperature is directly related to the increase of the radius of the nano-spheres composing the sensing material. After testing MOX sensors, in previous works [10,11], with firing temperatures ranging between 650 and $950^{\circ} \mathrm{C}$, we have chosen the firing

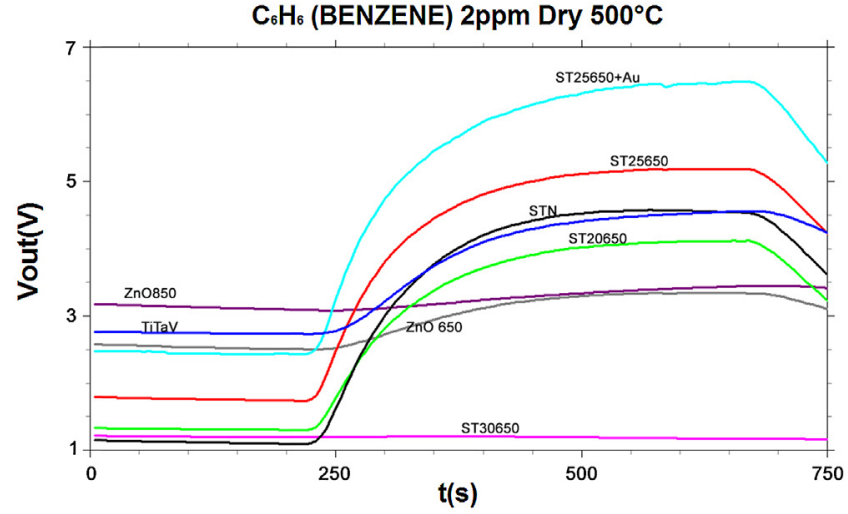

Fig. 3. Example of sensors response to $\mathrm{C}_{6} \mathrm{H}_{6}$ before normalization. On the $y$-axes there is the output voltage $\left(V_{\text {out }}\right)$.

temperatures $650^{\circ} \mathrm{C}$ (for tin/titanium-oxide-based sensors) and $850^{\circ} \mathrm{C}$ (for the zinc-oxide-based sensor) as the ones at which they give the highest response. The most common formulation for screen-printable paste is listed in Tab.11.9 of the book Printed films: Materials science and applications in sensors, electronics and photonics [13]. As reported on pag. 298 of the book, specific paste compositions are highly proprietary. The thickness of the sensing layers is about $30 \mu \mathrm{m}$ (thick film sensors) and they were obtained by screen-print pastes synthetized from these powders (by adding a proper amount of organic vehicles) onto miniaturized alumina substrates equipped with pre-deposited electrodes and the heater [12]. The gas sensing measurements were performed by means of the flow-through technique [13-15].

Responses from sensors are given by the dimensionless formula:

$R=\frac{V_{\text {plateau }}}{V_{\text {baseline }}}$

which removes all the dependence of the sensors response on the geometry. Fig. 3 shows an example of sensors response to $\mathrm{C}_{6} \mathrm{H}_{6}$ before normalization. The material characterization was carried out by using scanning electron microscopy (SEM). A SEM image of the film is shown in Fig. 4 to appreciate the morphology.

\subsection{Experimental setup}

The sensors were located into a gas flow chamber, inside which an artificial atmosphere were injected and controlled by pc-driven mass-flow controllers. The gases were from certified bottles and

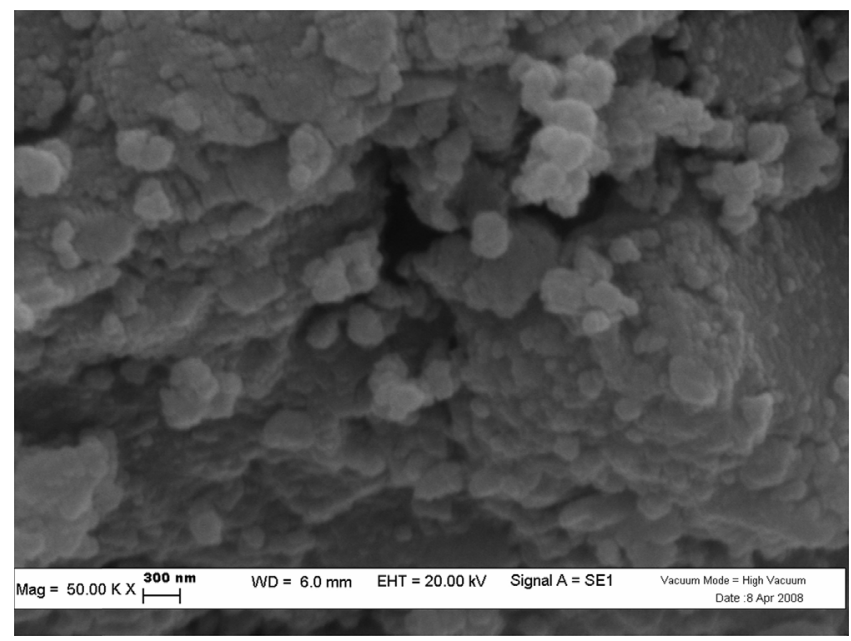

Fig. 4. SEM image of the sensor ST30 (tin and titanium oxide) fired at $650^{\circ} \mathrm{C}$. 


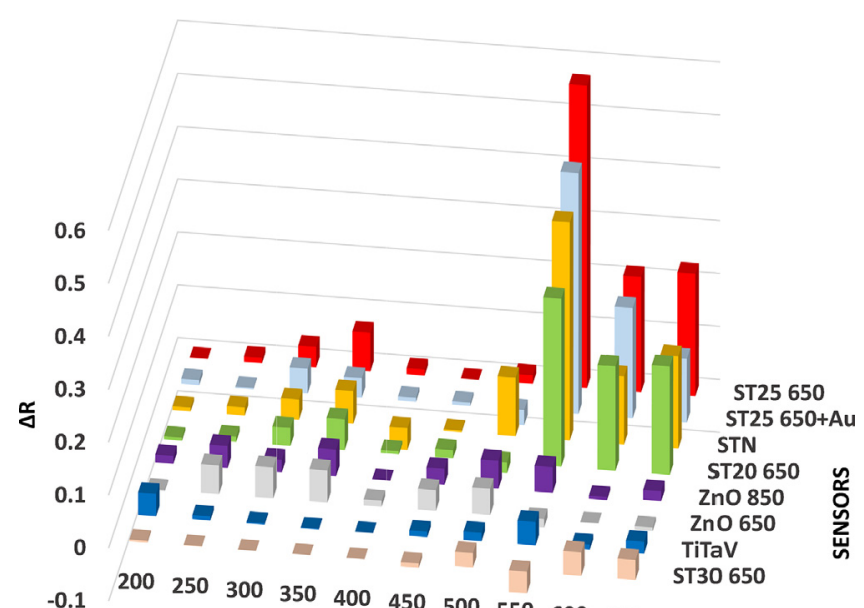

$-0.1$

$200 \quad 250300 \quad 350 \quad 400 \quad 450005050$ $\mathrm{T}\left({ }^{\circ} \mathrm{C}\right)$

Fig. 5. Subtraction between successive plateaus of $\mathrm{N}_{2}$ and dry synthetic air interferences, normalized over their baseline. The $\Delta$ shows the difference of responses for that temperature to the variation, for addition, of $5 \mathrm{sccm}$ of $\mathrm{O}_{2}$ in the $500 \mathrm{sccm}$ of the chamber.

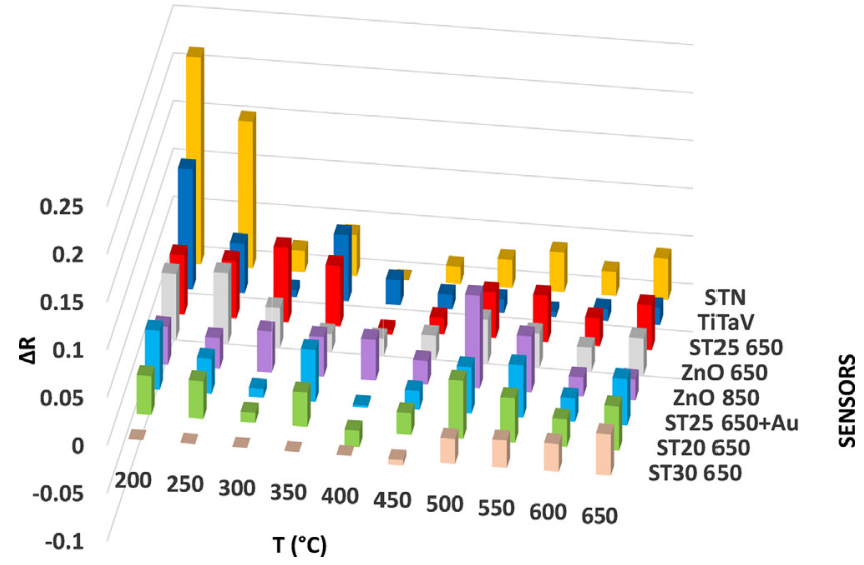

Fig. 6. Subtraction between successive plateaus of $\mathrm{N}_{2}$ and wet synthetic air interferences, normalized over their baseline. The $\Delta$ shows the difference of responses for that temperature to the variation, for addition, of $5 \mathrm{sccm}$ of $\mathrm{O}_{2}$ in the $500 \mathrm{sccm}$ of the chamber.

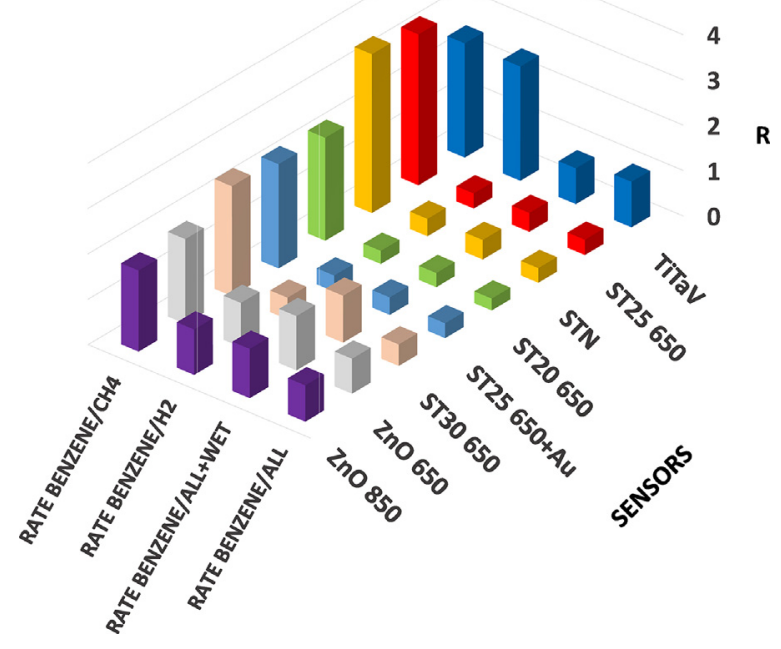

Fig. 7. Analysis of the total and partial response rates (ratio between responses) of the sensors array to $\mathrm{C}_{6} \mathrm{H}_{6}(5 \mathrm{ppm})$ in a mixture of $\mathrm{CH}_{4}(10 \mathrm{ppm}), \mathrm{H}_{2}(60 \mathrm{ppm})$ and dry air $\left(\mathrm{N}_{2}: 80 \%, \mathrm{O}_{2}: 20 \%\right)$. Humidity is used as an interferer.

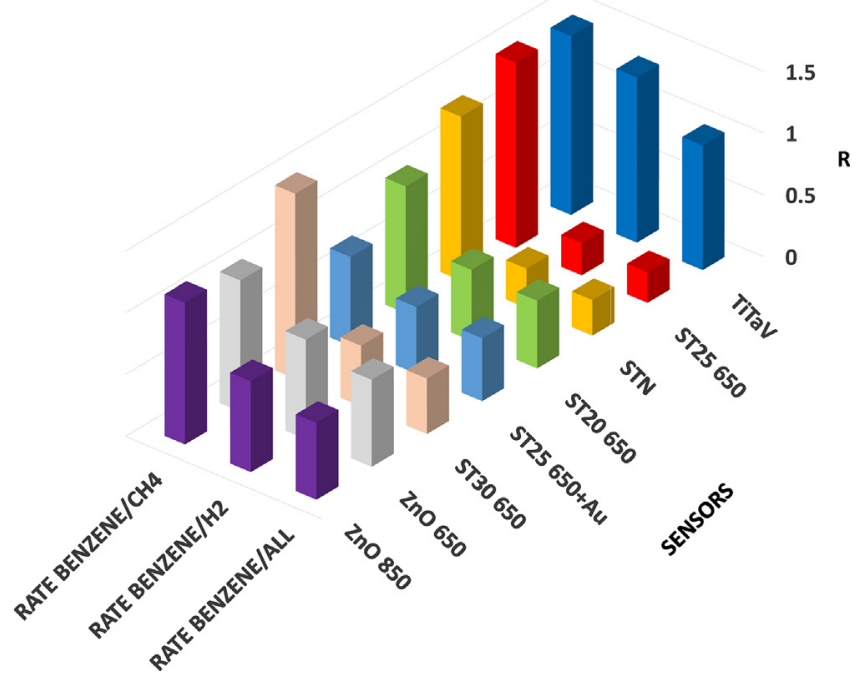

Fig. 8. analysis of the total and partial response rates (ratio between responses) of the sensors array to $\mathrm{C}_{6} \mathrm{H}_{6}(2 \mathrm{ppm})$ in a mixture of $\mathrm{CH}_{4}(10 \mathrm{ppm}), \mathrm{H}_{2}(60 \mathrm{ppm})$ and wet air $\left(\mathrm{N}_{2}: 80 \%, \mathrm{O}_{2}: 20 \%\right.$, RH: $\left.38 \%\right)$.

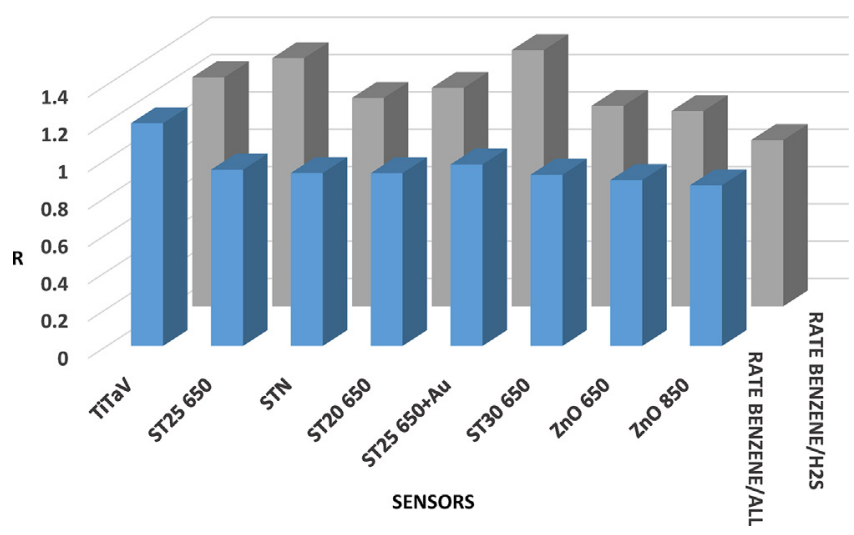

Fig. 9. Sensor responses to $\mathrm{C}_{6} \mathrm{H}_{6}(2 \mathrm{ppm})$ inside a mixture of wet air ( $\left.\mathrm{RH} \sim 20 \%\right)$ and two minor intestinal interfering gases $\mathrm{NO}_{2}(2 \mathrm{ppm})$ and $\mathrm{H}_{2} \mathrm{~S}(20 \mathrm{ppm})$. Temperature chosen are the ones at which the sensor responses to $\mathrm{NO}_{2}$ become negligible. Benzene is well detected into this partial interfering ambient.

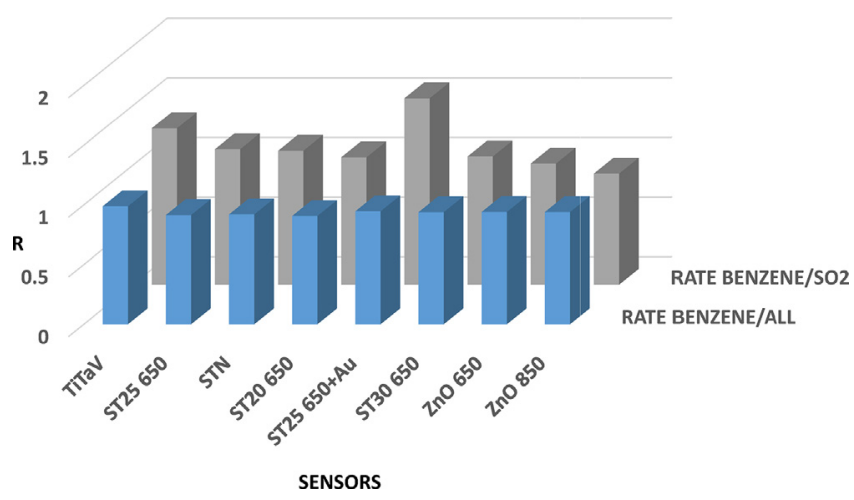

Fig. 10. Sensor responses to $\mathrm{C}_{6} \mathrm{H}_{6}(2 \mathrm{ppm})$ inside a mixture of wet air $(\mathrm{RH} \sim 34 \%)$ and two minor intestinal interfering gases $\mathrm{NO}(2 \mathrm{ppm})$ and $\mathrm{SO}_{2}(2 \mathrm{ppm})$. Temperature chosen are the ones at which the sensor responses to NO become negligible. Benzene is well detected into this partial interfering ambient.

the vapors of 1-iodo-nonane and decanal were supplied by means of a bubbler with the proper amount of the liquids. The scheme of the experimental setup is shown in Fig. 5 published in our previous work Malagù et al. [1]. 
INTERFERENCE C6H6 (2ppm) vs NO (2ppm) + SO2 (2ppm) Dry (NO Best Rate)

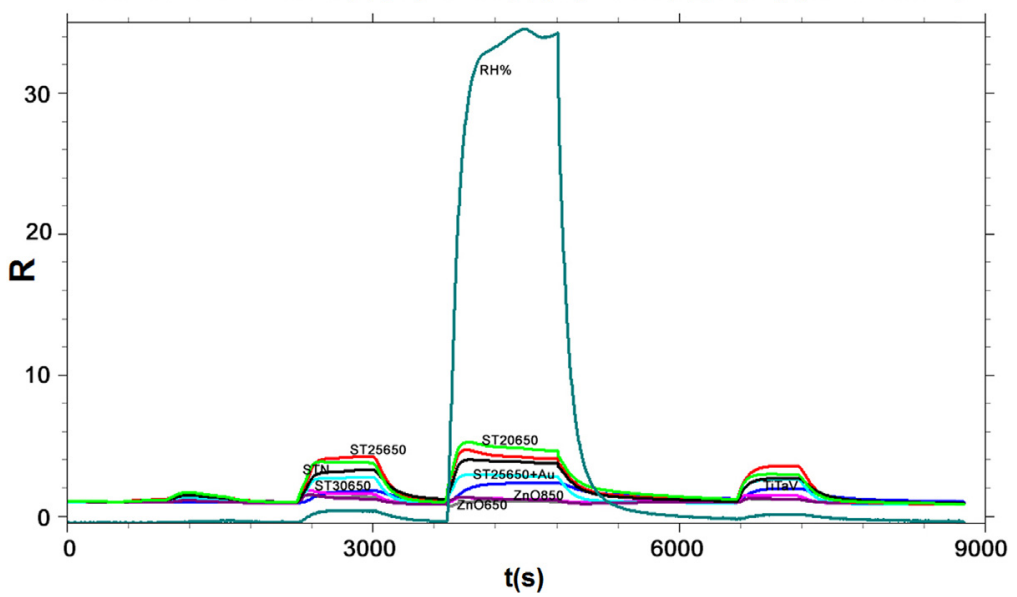

Fig. 11. Sensor responses, as a function of time, to $\mathrm{SO}_{2}$ (1st peak), $\mathrm{C}_{6} \mathrm{H}_{6}+\mathrm{SO}_{2}+\mathrm{NO}$ (2nd peak), $\mathrm{C}_{6} \mathrm{H}_{6}+\mathrm{SO}_{2}+\mathrm{NO}+$ wet air (3rd peak), $\mathrm{C}_{6} \mathrm{H}_{6}$ (4th peak) in dry conditions. Temperature chosen are the ones at which the sensor responses to NO become negligible.

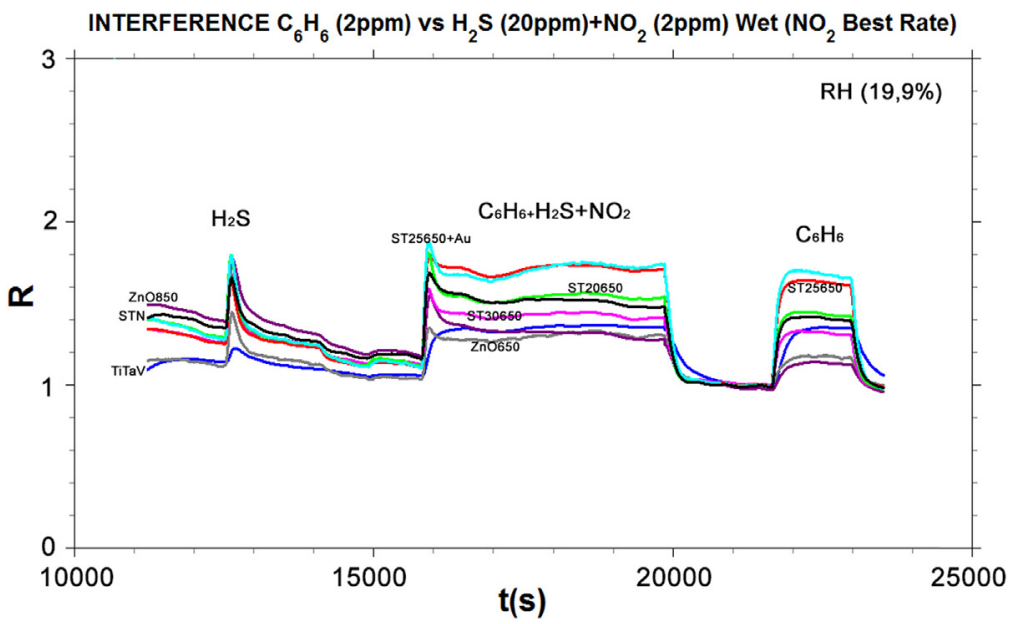

Fig. 12. Sensor responses, as a function of time, to $\mathrm{H}_{2} \mathrm{~S}$ (1st peak), $\mathrm{C}_{6} \mathrm{H}_{6}+\mathrm{H}_{2} \mathrm{~S}+\mathrm{NO}_{2}$ (2nd peak), $\mathrm{C}_{6} \mathrm{H}_{6}$ (3rd peak) in wet conditions RH: 20\%. Temperature chosen are the ones at which the sensor responses to $\mathrm{NO}_{2}$ become negligible.

The response to the target gases was observed for different working temperatures both in dry ( $\mathrm{RH} \sim 0 \%)$ and in wet conditions $(18 \%<\mathrm{RH}<60 \%)$. Choosing the most favorable temperatures of each sensor for benzene detection, the intestinal standard gas mixture was approximately reproduced into the sensors chamber. $\mathrm{CO}_{2}$ is not considered because it is well known that it is hardly detected by chemoresistive sensors [13]. During the experiment testing measurements were done on dry and wet air with the purpose to check

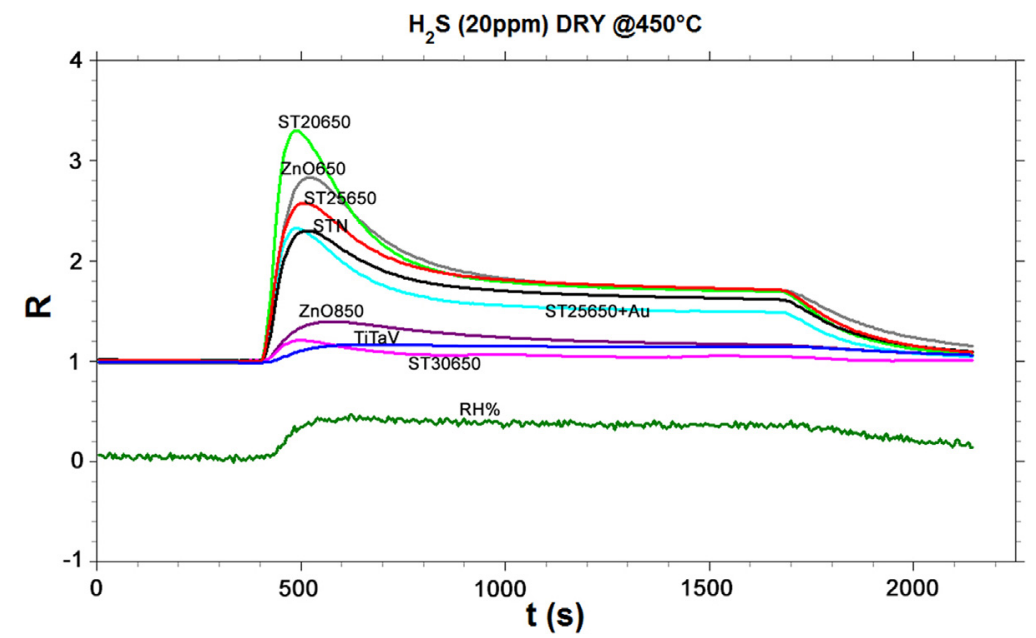

Fig. 13. Sensor responses, as a function of time, to $\mathrm{H}_{2} \mathrm{~S}$ in dry conditions at $450{ }^{\circ} \mathrm{C}$. Humidity increases when $\mathrm{H}_{2} \mathrm{~S}$ is inflated, due to the reaction (1), described in the text. 


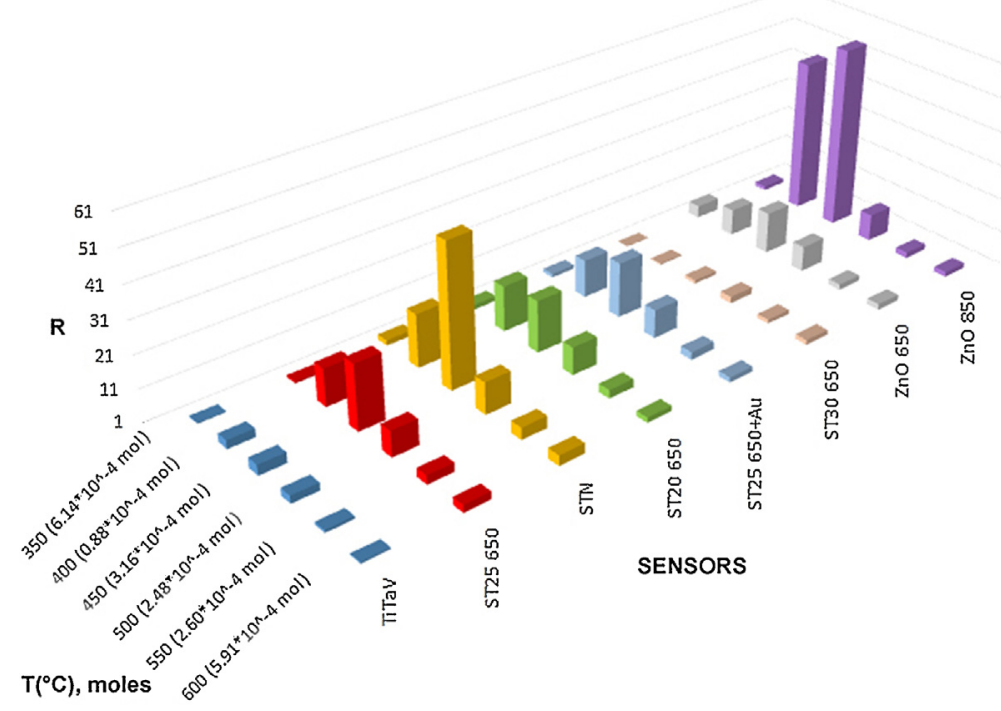

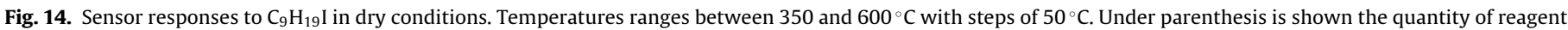
(moles) taken for each measure.

the differences of response on the variation of humidity, operating temperature, and oxidation of the films. It is important to state the effects of the variations of oxygen on the sensors responses for three main reasons: (i) in the intestine there are variations of oxygen production due to the digestive, bacterial and cellular activity; (ii) there are some chemical reaction that occur between oxygen and other compounds both in the intestine and in the experimental setup; (iii) some bottles used in the experimental tests cannot contain oxygen for safety reasons but contain $\mathrm{N}_{2}$ (i.e. $\mathrm{H}_{2}$ ). For these reasons the total volume of the chamber was filled with $\mathrm{N}_{2}$ and $\mathrm{O}_{2}$ in different concentrations, using at first a flow of synthetic dry or wet air with $20 \% \mathrm{O}_{2}$ and $80 \% \mathrm{~N}_{2}$. Then, with the addition of a flow of pure $\mathrm{N}_{2}$ and the lowering of the synthetic air flow, the ratio between $\mathrm{O}_{2}$ and $\mathrm{N}_{2}$ in the chamber was modified (increasing $\mathrm{O}_{2}$ volume concentration of $1 \%$ ), obtaining so a detailed analysis of the disturbance from environmental changes and differences on metal oxide films (Figs. 5 and 6). We defined with the symbol
$\Delta$ the difference between responses in the two cases described before.

Regarding decanal and 1-iodo-nonane, it is important to notice that the reported number of moles represents an upper limit, obtained from the subtraction in weight of the drops of compounds from the pipette; due to the uncontrollability of the evaporative process and the non-hermetical lockup of the gas bubbler, part of the dose can be assumed not to have reached the sensors at all.

Tests with 1-iodo-nonane were made in dry conditions, using an empty gas bubbler to evaporate it; no solvents were used to haste the evaporation of $\mathrm{C}_{9} \mathrm{H}_{19}$ I, due to the high responses of sensors to alcohols and other organic reagents like dichloromethane $\left(\mathrm{CH}_{2} \mathrm{Cl}_{2}\right)$. The weight of the reagent was measured with a precision balance, to calculate the number of moles and to obtain an average value of the concentration. To identify the best detecting temperature for each type of sensing material, we tested the response at several working temperatures $\left(350,400,450,500,550,600^{\circ} \mathrm{C}\right)$.

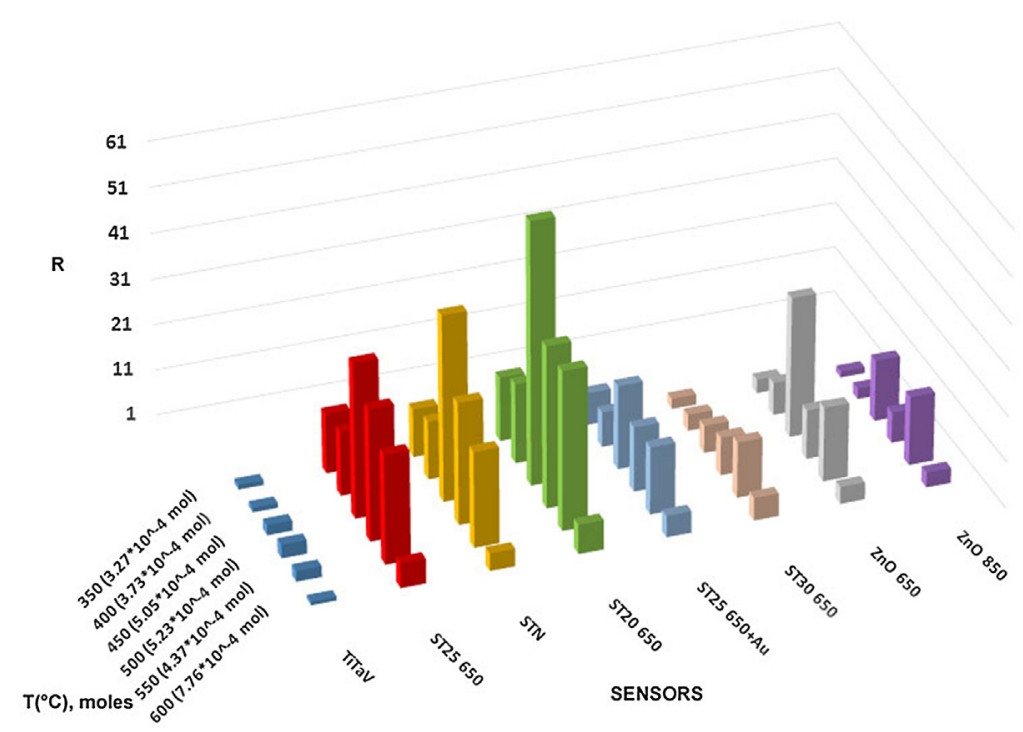

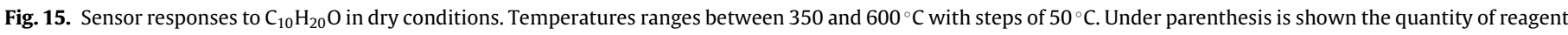
(moles) taken for each measure. 


\section{Experimental results}

\subsection{Benzene $\left(\mathrm{C}_{6} \mathrm{H}_{6}\right)$}

Fig. 7 shows the responses of the sensors array to $5 \mathrm{ppm}$ of benzene in dry conditions, together with a mixture of $\mathrm{CH}_{4}(10 \mathrm{ppm})$ and $\mathrm{H}_{2}(60 \mathrm{ppm})$ as interferes, and synthetic dry air $\left(80 \% \mathrm{~N}_{2}\right.$ and $\left.20 \% \mathrm{O}_{2}\right)$, while in Fig. 8 the same atmosphere is reproduced in wet conditions (RH: 38\%). These concentrations were selected to simulate the intestinal atmosphere. Experimental data show that hydrogen is the most influent interferer, always resulting in very high response. However, it can be noticed that the TiTaV sensor (titanium, tantalum, vanadium oxides) was not sensitive to it, and it showed a great selectivity to small quantities of $\mathrm{C}_{6} \mathrm{H}_{6}$ even in the presence of hydrogen. This confirms the good capability of TiTaV to detect benzene only [1] or in presence of interferers (Figs. 9 and 10). Other interference tests with secondary interferes like $\mathrm{H}_{2} \mathrm{~S}, \mathrm{SO}_{2}, \mathrm{NO}_{2}$ and $\mathrm{NO}$ were made both in dry and wet conditions. The concentrations of these interferes were $20 \mathrm{ppm}$ for $\mathrm{H}_{2} \mathrm{~S}$ and $2 \mathrm{ppm}$ for all others, to reproduce real concentrations in the intestine [16]. Measurements were made at the best working temperature for each sensor $\left(T_{\text {best }}\right)$ to have the higher selectivity for benzene with respect to the contribution of interferes. Observing Figs. 11 and 12 it is evident that, both in wet and dry conditions, the sensors responses to benzene is considerably higher compared to that of interferers. These interferers were chosen because they are gasotransmitters (NO) [17] normally present in human gut, products of the bacterial activity in human stomach and intestine $\left(\mathrm{NO}_{x}\right.$ family [17-19]) or of highly reactive digestion processes $\left(\mathrm{H}_{2} \mathrm{~S}\right)$.

$\mathrm{SO}_{2}$ was tested to verify the occurring of the chemical reaction

$2 \mathrm{H}_{2} \mathrm{~S}+3 \mathrm{O}_{2} \rightarrow 2 \mathrm{H}_{2} \mathrm{O}+2 \mathrm{SO}_{2}$,

which represents the combustion of $\mathrm{H}_{2} \mathrm{~S}$ which happens at high temperatures on the surface of the sensing films $\left(\mathrm{H}_{2} \mathrm{~S}\right.$ autocombustion occurs at $260^{\circ} \mathrm{C}$ ) [20,21]. Its signature is visible from the initial peak of response before reaching the plateau, then it gradually reduces with time, due to the increasing relative humidity caused by the surface reaction (1) (Fig. 13).

\subsection{1-Iodo-nonane $\left(\mathrm{C}_{9} \mathrm{H}_{19} \mathrm{I}\right)$}

Observing Fig. 14, the ZnO 850 sensor (zinc oxide, fired at $850^{\circ} \mathrm{C}$ ) and STN (tin, tantalum, niobium oxides) are the ones that give the best responses to this compound, confirming results for tin oxidebased sensors of a previous work [1], in wet conditions. Humidity does not change the trend of the responses to 1-iodo-nonane but reduces only their value. TiTaV, which is selective to benzene, shows a low response to this compound. 1-iodo-nonane is sensitive to light, so all the dropping procedures and weight measurements have been done in conditions of darkness to preserve the original state of the compound [22].

\subsection{Decanal $\left(\mathrm{C}_{10} \mathrm{H}_{20} \mathrm{O}\right)$}

Tests with decanal were made in dry ambient with the same procedure used for 1-iodo-nonane and with the same sensors array. Responses are summarized in Fig. 15. The sensors ST20 650, STN and ST25 650 are the best responding ones to decanal. This evidence highlights the property of tin oxide-based films to have a high response to this VOC, instead TiTaV does not show much affinity to it. As with 1-iodo-nonane, the weighing and deposition of the drops of decanal have been done in darkness; $\mathrm{C}_{10} \mathrm{H}_{20} \mathrm{O}$ is in fact also air sensitive, but it is still light activating the process of auto-oxidation leading to first peroxo-acids production and thus to alteration on the compound [23].
INTERFERENCE $\mathrm{C}_{10} \mathrm{H}_{20} \mathrm{O}\left(7.46 \times 10^{-} \mathrm{mol}\right)+\mathrm{C}_{9} \mathrm{H}_{19}\left(2.57 \times 10^{-4} \mathrm{~mol}\right) @ 450^{\circ} \mathrm{C}$ DRY 13

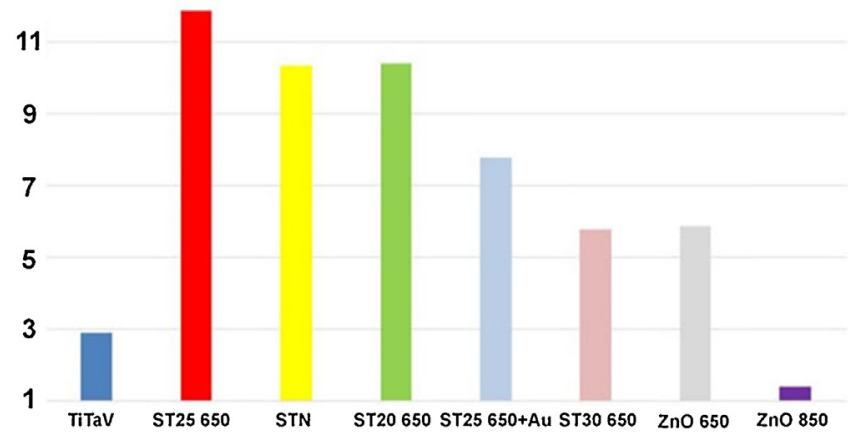

Fig. 16. Sensor responses to $\mathrm{C}_{9} \mathrm{H}_{19} \mathrm{I}$ and $\mathrm{C}_{10} \mathrm{H}_{20} \mathrm{O}$ in combination, in wet conditions. Working temperature of all sensors is fixed at $450^{\circ} \mathrm{C}$. Under parenthesis is shown the quantity of reagent (moles) taken for each measure.

Table 2

Sensor responses at their best working temperature to various VOC. Responses are given as rates between the tensions measured for the plateaus over their original baseline.

\begin{tabular}{lllc}
\hline Sensors & Temperature $\left({ }^{\circ} \mathrm{C}\right)$ & Gas target & Response \\
\hline TiTaV & 450 & Benzene & 1.9 \\
ZnO 850 & 450 & 1-Iodo-nonane & 56.9 \\
STN & 450 & 1-Iodo-nonane & 45.1 \\
ST20 650 & 450 & Decanal & 58.4 \\
STN & 450 & Decanal & 41.6 \\
ST25 650 & 450 & Decanal & 34.8 \\
ZnO 650 & 450 & Decanal & 31.6 \\
\hline
\end{tabular}

\subsection{Interference tests in wet air: $\mathrm{C}_{9} \mathrm{H}_{19} \mathrm{I}$ and $\mathrm{C}_{10} \mathrm{H}_{20} \mathrm{O}$}

We made a test with 1-iodo-nonane $\left(2.57 \times 10^{-4} \mathrm{~mol}\right)$ and decanal $\left(7.46 \times 10^{-4} \mathrm{~mol}\right)$ in combination, in wet conditions, to check if the interference of the two VOCs can alter the sensors responses observed in the previous measurements. The chosen working temperature was the same for all sensors $\left(450^{\circ} \mathrm{C}\right)$. Results are shown in Fig. 16. The response of tin oxide-based sensors remains high while the $\mathrm{ZnO} 850$, the most sensitive material for 1-iodo-nonane, shows a low response.

\section{Conclusions}

A set of sensors made of single and mixed metal oxides has been selected to detect benzene, 1 -iodo-nonane and decanal. An array of sensors was then obtained combining different materials working at their best temperatures, which proved to be highly selective to these gases, also in a background of realistic concentrations of $\mathrm{H}_{2}, \mathrm{CH}_{4}, \mathrm{H}_{2} \mathrm{~S}, \mathrm{SO}_{2}, \mathrm{~N}_{2}, \mathrm{NO}_{2}$ and $\mathrm{NO}$, in different environmental conditions. TiTaV showed the highest selectivity to $\mathrm{C}_{6} \mathrm{H}_{6}$ against primary interferers as $\mathrm{H}_{2}$ and $\mathrm{CH}_{4}$, emerging as the best sensor for this biomarker. Tests on aldehydes (1-iodo-nonane and decanal) showed refractoriness of TiTaV on responding to this family of compounds, while tin oxide and zinc oxide-based sensors (in particular, ZnO 850 and STN for 1-iodo-nonane and ST20 650, STN and ST25 650 for decanal) are preferable for the detection of this kind of markers. In fact their relative responses are up to 20 times higher (Figs. 13 and 14) than those of TiTaV.

According to these results, we proved that, even for really low concentrations (2-5 ppm for benzene, and doses on the order of $10^{-4} \mathrm{~mol}$ of 1 -iodo-nonane and decanal), and with different temperature and humidity conditions, chemoresistive sensors can show huge responses once set at their proper working temperatures (Table 2). This confirms the applicability of chemoresistive gas sensors as tumor marker detectors, leading to interesting 
possibilities to enhance the health system and improving chances for preventive screening of tumors.

\section{References}

[1] C. Malagù, B. Fabbri, S. Gherardi, A. Giberti, V. Guidi, N. Landini, G. Zonta, Chemoresistive gas sensors for detection of colorectal cancer biomarkers, Sensors (2014) 18982-18992.

[2] H. Haick, Y.Y. Broza, P. Mochalsky, V. Ruzsanyi, A. Amann, Assessment, origin and implementation of breath volatile cancer markers, Chem. Soc. Rev. 43 (2014) 1423-1449.

[3] B. Tan, Y. Oi, X. Zou, T. Chen, G. Xie, Y. Cheng, T. Dong, L. Zhao, B. Feng, X Hu, L.X. Xu, A. Zhao, M. Zhang, G. Cai, S. Cai, Z. Zhou, M. Zheng, Y. Zhang, W. Jia, Metabonomics identifies serum metabolite markers of colorectal cancer, J. Proteome Res. 12 (6) (2013) 3000-3009.

[4] G. Peng, M. Hakim, Detection of lung, breast, colorectal, and prostate cancers from exhaled breath using a single array of nanosensors, Br. J. Cancer 103 (2010) $542-551$.

[5] C.S.J. Probert, I. Ahmed, T. Khalid, E. Johnson, S. Smith, N. Ratcliffe, Volatile organic compounds as diagnostic biomarkers in gastrointestinal and liver diseases, J. Gastrointest. Liver Dis. 18 (3) (2009) 337-343.

[6] D.F. Altomare, M. Di Lena, Exhaled Volatile Organic Compounds Identify Patients With Colorectal Cancer, Wiley Online Library, 2013.

[7] G. Ghiotti, A. Chiorino, Preparation and characterization of $\mathrm{WO}_{x} / \mathrm{SnO}_{2}$ nanosized powders for thick films gas sensor, Stud. Surf. Sci. Catal. 140 (2001) 287-296.

[8] M. Benetti, M. Blo, Symplectic gel co-precipitation of $\mathrm{Ti}_{\mathrm{x}} \mathrm{Sn}_{1-\mathrm{x}} \mathrm{O}_{2}$ solid solutions for gas sensing, in: Proceedings of the Eurosensors XIX, Barcelona, Spain, 11-14 September, 2005

[9] M.C. Carotta, M. Benetti, Nanostructured ( $\mathrm{Sn}$, Ti, Nb)O 2 solid solutions for hydrogen sensing, in: Proceedings of the Materials Research Society Spring Meeting, San Francisco, CA, USA, 17-21 April, 2000, p. 68210.

[10] M.C. Carotta, A. Cervia, V. di Natale, S. Gherardi, A. Giberti, V. Guidi, D. Puzzovio, B. Vendemiati, G. Martinelli, M. Sacerdoti, D. Calestani, A. Zappettini, M. Zha, L. Zanotti, ZnO gas sensors: a comparison between nanoparticles and nanotetrapods-based thick films, Sens. Actuators B 137 (1) (2009) 164-169.

[11] M.C. Carotta, M. Feroni, D. Gnani, V. Guidi, M. Merli, G. Martinelli, M.C. Casale, M. Notaro, Nanostructured pure and Nb-doped $\mathrm{TiO}_{2}$ as thick film gas sensors for environmental monitoring, Sens. Actuators B 58 (1999) 310-317.

[12] M.C. Carotta, V. Guidi, Vanadium and tantalum-doped titanium oxide (TiTaV): a novel material for gas sensing, Sens. Actuators B 108 (2005) 89-96.

[13] V. Guidi, C. Malagu', M.C. Carotta, B. Vendemiati, Printed Films: Materials Science and Applications in Sensors, Electronics and Photonics, Woodhead Publishing Series in Electronic and Optical Materials, 2012, pp. 278-334.

[14] M.C. Carotta, A. Cervi, Metal-oxide solid solutions for light alkane sensing, Sens. Actuators B 133 (2008) 516-520.

[15] M.C. Carotta, A. Cervi, Ethanol interference in light alkane sensing by metal-oxide solid solutions, Sens. Actuators B 136 (2009) 405-409.

[16] A.B. Sahakian, S.R. Jee, M. Pimentel, Methane and the gastrointestinal tract, Dig. Dis. Sci. 55 (8) (2010) 2135-2143.

[17] J. Vermeiren, T. Van deWiele, W. Verstraete, P. Boeckx, N. Boon, Nitric oxide production by the human intestinal microbiota by dissimilatory nitrate reduction to ammonium, J. Biomed. Biotechnol. 2009 (2009).

[18] A. Tari, K. Kodama, K. Kurihara, M. Fujihara, K. Sumii, G. Kajiyama, Does serum nitrite concentration reflect gastric carcinogenesis in Japanese Helicobacter pylori-infected patients, Dig. Dis. Sci. 47 (1) (2002) 100-106.

[19] T. Kondo, T. Mitsui, M. Kitagawa, Y. Nakae, Association of fasting breath nitrous oxide concentration with gastric juice nitrate and nitrite concentrations and Helicobacter pylori infection, Dig. Dis. Sci. 45 (10) (2000) 2054-2057.

[20] J.A. Rodriguez, S. Chaturvedi, M. Kuhn, J. Hrbek, Reaction of $\mathrm{H}_{2} \mathrm{~S}$ and $\mathrm{S}_{2}$ with metal/oxide surfaces: band-gap size and chemical reactivity, J. Phys. Chem. B $102(28)(1998) 5511-5519$

[21] <http://www.inchem.org/documents/icsc/icsc/eics0165.htm>.

[22] <http://www.chemspider.com/Chemical-Structure.19101.html>

[23] <http://www.chemicalbook.com/ChemicalProductProperty_EN_CB2208008. htm>.

\section{Biographies}

Giulia Zonta She received the Bachelor's Degree in Physics and Astrophysics in December 2010 (110/110 cum laude) and the Master's Degree in Physics in October
2013 (110/110), at the University of Ferrara. In January 2014 she started her Ph.D. in Matter Physics, working with the Sensors Team, coordinated by Dr. Cesare Malagù. In the April of the same year she obtained the recognition "Ferrara School of Physics", that rewards the internationality of her Master's thesis work. Currently her research focuses on the study of the physic-chemical behavior of chemoresistive nanostructured gas sensors, put in contact with volatile organic compounds (VOCs) of medical interest. With her team she won Unife Cup 2013, a business plan competition that rewards innovative start-ups and Start Cup Emilia Romagna 2014, with the objective to create a start-up for the realization of devices for medical screenings. Now she is the co-supervisor of two students who are working for the Bachelor's and Master's Degree in Physics, respectively.

Gabriele Anania was born in 1962, Italy. In 2013 he resulted adequate for the role of Associated professor in competitive exam of Scientific National Abilitation, in sector 06/C1 - General Surgery (Bando 2012 DD n. 222/2012). In 2001 he resulted winner of the title of academic researcher reserved to "Università degli Studi di Ferrara" personnel with all the requirements asked by the law 4/1999 declared with L.D. n.159 on 26/09/2000. 1st level medical supervisor at surgery department of "Azienda Ospedale-Università S. Anna di Ferrara". In 1999 he was assigned at Surgery clinic section of surgery, radiology and anesthetic sciences department of "Facoltà di Medicina e Chirurgia dell'Università degli Studi di Ferrara" directed by Prof. Ippolito Donini. Now he has the role of Associated Professor at the University of Ferrara.

Barbara Fabbri She obtained her Master Degree in Physics at University of Ferrara in 2011. Currently she is a PhD student involved in the field of gas sensors and micromachining.

Andrea Gaiardo He obtained his Degree in Chemistry at the University of Ferrara in 2011 and the Master's Degree in Chemical Sciences at the University of Ferrara in 2013. Now, his work is focused in the field of innovative inorganic semiconductors for applications in gas sensing. He started his $\mathrm{PhD}$ in Physics at the University of Ferrara in November 2014.

Sandro Gherardi Bachelor in Physics Technologies at the University of Ferrara in 2002. Research activity carried out at the Sensors and Semiconductors laboratory of the University of Ferrara about gas sensing and industrial applications of monitoring devices by nanostructured semiconductor based sensors

Alessio Giberti Bachelor in Theoretical Physics at the University of Ferrara in 2000 he obtained PhD in Physics of Matter in 2004 at the Physics Department of the University of Ferrara. His research since $\mathrm{PhD}$ is focused on the field of semiconductor gas sensors based on nanostructured metal oxides, with particular interest toward the electrical and selectivity properties.

Vincenzo Guidi Bachelor in Physics at the University of Ferrara in 1990, fellow at "Budker Institute for Nuclear Physics" of Novosibirsk (Russia) in 1991. Thesis of doctorate in experimental physics at Legnaro National Laboratories in 1994. Researcher in experimental physics at University of Ferrara. Research activity, carried out at the Sensors and Semiconductors laboratory of the University of Ferrara, has consisted of investigations on basic phenomena in semiconductors and to practical implementations of sensing devices. Author of more than 140 articles in peer-reviewed journals and of more than 100 contributions to the proceedings of international conferences, reviewer and/or editors of numerous journals of Physics and Electronics, organizer of several national and international conferences and editor of the proceedings.

Nicolò Landini Bachelor in Physics and Astrophisics at the University of Ferrara in 2011. He is a graduating student in Physics (Master's Degree) under the supervision of Dr. Cesare Malagù, working with chemoresistive gas sensors with biomedical applications.

Cesare Malagù Cesare Malagù was born in 1974 in Ferrara, Italy. He received a degree in Physics at the University of Ferrara in 1997 (Summa Cum Laude) and the Ph.D. degree in experimental physics in 2001 . He has been teaching General Physics since 2001 and works as a Lecturer and Aggregated Professor since 2007. His research activity is mainly based on modeling of transport phenomena in nanostructured semiconductors. His expertise is in thick film technology applied to environmenta and energetic sustainability. He has more than 60 papers in peer reviewed journals (Hirsch index 23) and numerous proceedings and invited lectures, moreover he is in the editorial board of several journals. He coordinates the sensors group at the University of Ferrara and teaches General Physics II and a course of Sensors at the Department of Physics and Earth Science. 